\title{
Turvallisuuden värit
}

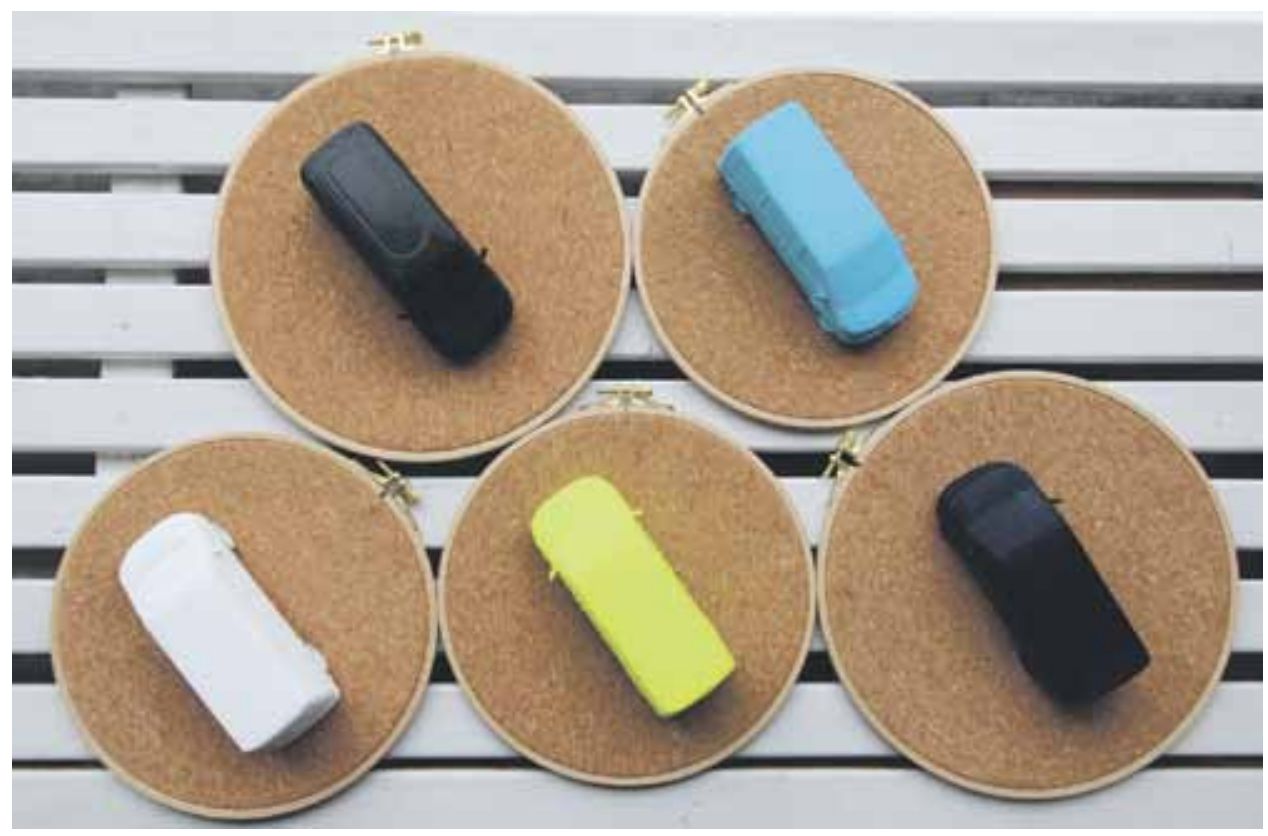

Tutkielma autoista.

Yhteiskuntatieteellinen tutkimus on pitkälti ollut värisokeaa tai oikeastaan täysin väritöntä. Värien käyttö on luettu merkityksenmuodostuksissa näkymättömyyden tai melun piiriin, värit on korkeintaan nähty esteettisinä tai muotoiluun liittyvinä piirteinä. Koneen säätiön rahoittama Turvallisuuden värit -hanke kuitenkin lähtee siitä, että värien käyttö ei ole "viatonta". Värit ovat elimellinen osa inhimillistä toimintaa sekä merkitysten muodostumista: ne ilmentävät ihmisten rakennettuja visuaalisuuksia ja nivoutuvat ihmisten, teknologioiden ja sosiaalisten merkitysten sykeröiksi sekä verkostoiksi. Tämä pätee yleisesti, mutta aivan erityisesti hankkeen tutkimuskohteena olevissa turvallisuuskäytännöissä. "Kromatologian" 
avulla on mahdollista tutkia värejä suhteessa ihmiseen ja turvallisuuteen (Andersen et al. 2015; Andersen et al. 2016; Guillaume et al. 2016; Guillaume et al. 2018; Vuori et al. 2020).

Hankkeen taitelijana toimivan Margarita Rosselló Ramónin mukaan taiteen kautta voidaan tutkia asioita tieteen lailla, mutta taiteella on käsissään vapaampi tulkintamahdollisuus. Toisinaan juuri sen vapauden kautta voidaan löytää uusia kiinnostavia näkökulmia. Taide toimii näin myös keskustelun tukena ja voi helpottaa tieteellisen tutkimuksen sisällön hahmottamista ja tuoda näin uusia ihmisiä aiheen pariin. Rosselló Ramón saa inspiraationsa lukemalla hankkeen tuottamia tekstejä sekä niihin liittyvää kirjallisuutta ja keskustelemalla niistä hankkeen tutkijoiden kanssa. Idea saattaa tulla jostain yksittäisestä sanasta, tietystä termistä tai laajemmasta käsitteestä.

Hankkeessa tuotetut teokset ovat hyvin käsitteellisiä. Niitä voi lähestyä puhtaan visuaaliselta pohjalta, mutta eniten niistä saa irti lukemalla mihin mikäkin teos linkittyy. Mikään valinta väreissä, muodoissa ja materiaaleissa ei ole sattumaa, vaan kokeiluiden kautta valikoitua. Lerppujen aukoissa olevat väripallot ovatkin ydinasevaltioiden lippujen värejä ("Game Theory"), valvontakamerapiirroksilla tarkastellaan teknologian kehitystä sekä vallan määrän näkymistä arjessa ("All Eyes on Us"; "Grayscale" yksityiskohta) ja vihreät nurmenpalaset viittaavat aiempaan rauhanväriin ("Piece of Grass"). Kaikella on merkityksensä. Joissain teoksissa esiintyy suoria tekstilainoja tai jopa kokonainen artikkeli installaation konkreettisena osana. Rosselló Ramónille teokset ovat projektin aiheisiin liittyviä pieniä tutkielmia, sanojen tuomista näkyväksi ja ajattelun yhdistämistä.

Teokset: Margarita Rosselló Ramón, kuvataiteilija Teksti: Juha A. Vuori, kansainvälisen politiikan professori

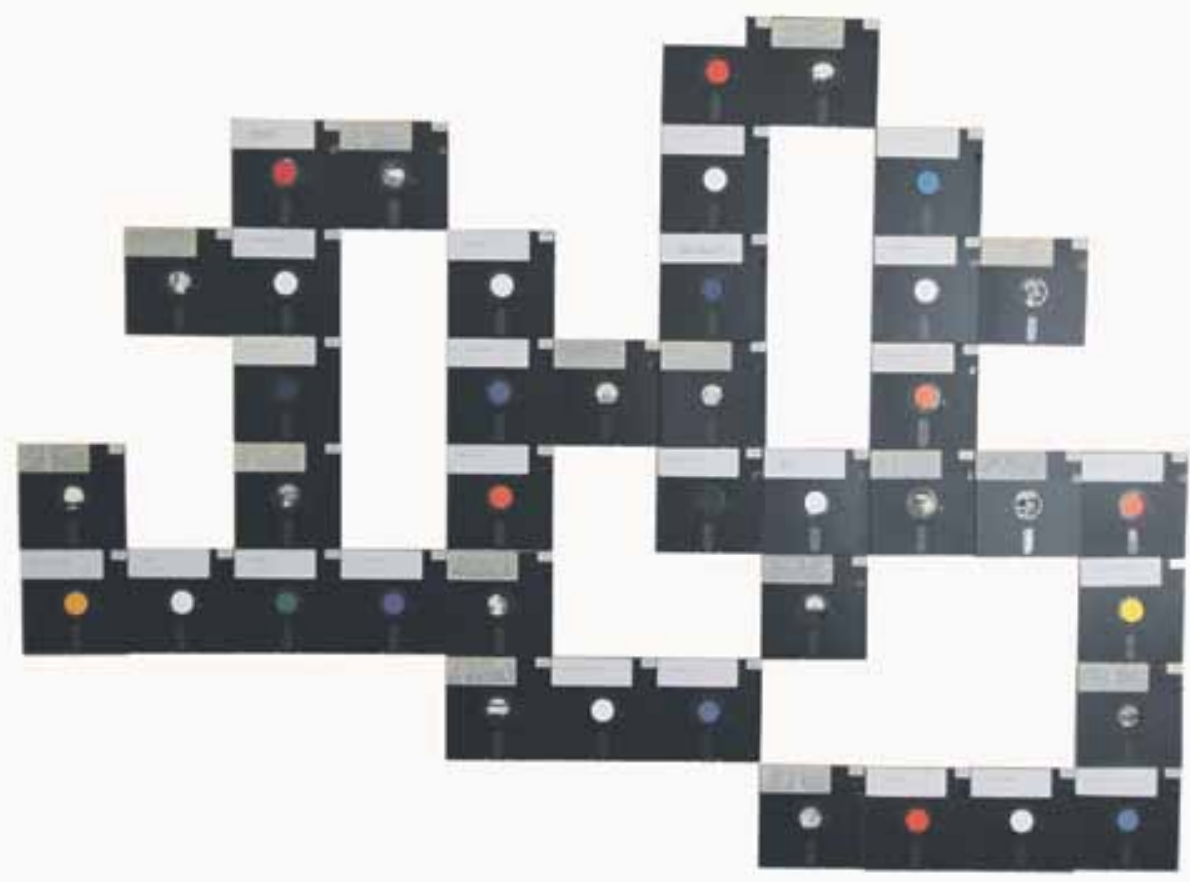

Game Theory. 


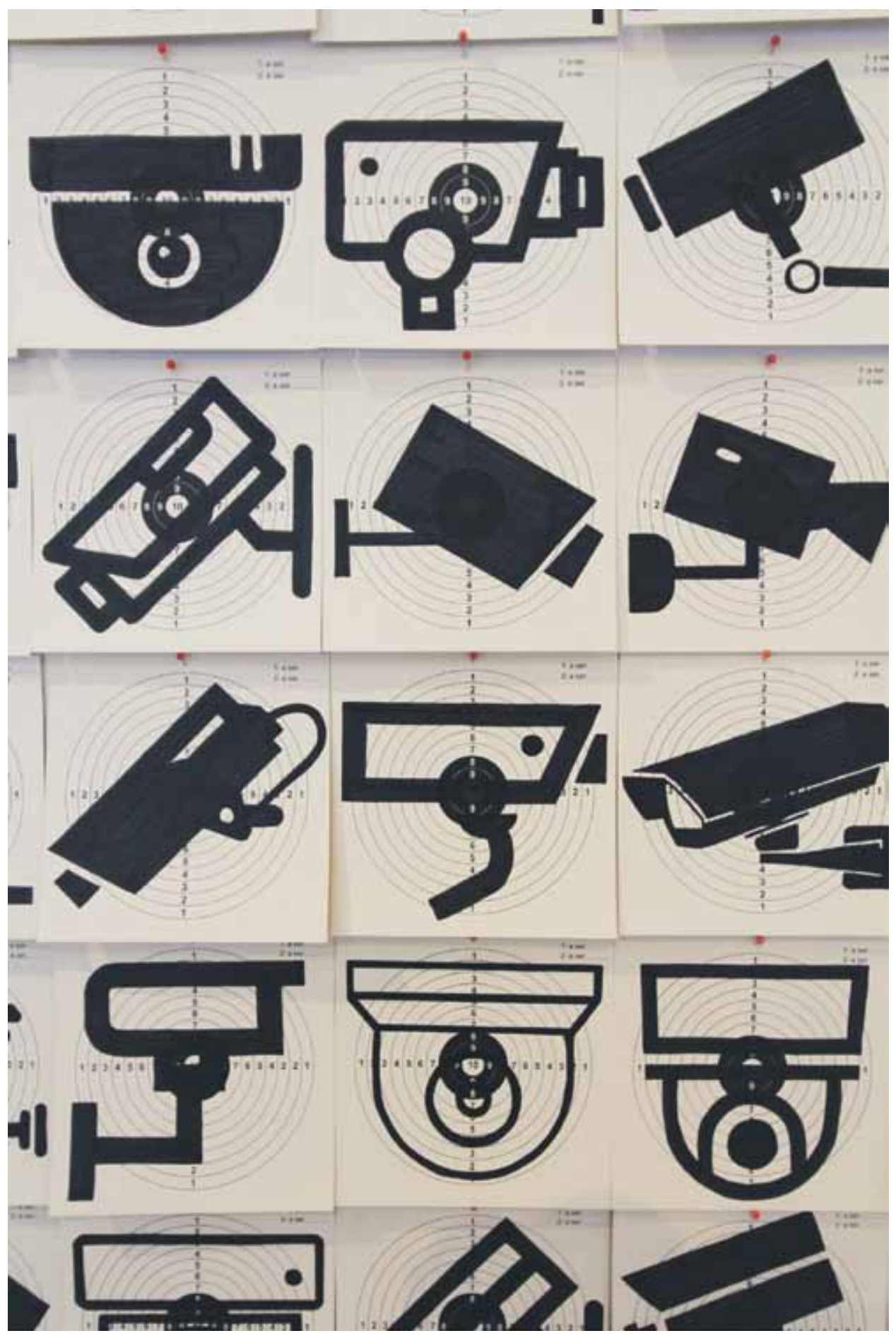

All Eyes on Us. 


\section{Viitteet:}

Andersen, Rune S. \& Vuori, Juha A. \& Guillaume, Xavier (2015), Chromatology of Security: Introducing Colours to Visual Security Studies. - Security Dialogue 46:5, 440-457.

Guillaume, Xavier \& Andersen, Rune S. \& Vuori, Juha A. (2016), Paint it Black: Colours and the Social Meaning of the Battlefield. - European Journal of International Relations 22:1, 49-71.

Andersen, Rune S. \& Guillaume, Xavier \& Vuori, Juha A. (2016), Flags. - Making Things International 2: Catalysts and Reactions. Ed. Mark B. Salter. Minneapolis: Minnesota University Press, 137-152.

Guillaume, Xavier \& Vuori, Juha A. \& Andersen, Rune S. (2018), Making norms visible: Police uniforms and the social meaning of policing. - Visual Security Studies: Sights and Spectacles of Insecurity and War. Eds Juha A. Vuori \& Rune S. Andersen. Lontoo, Routledge, 150-170.

Vuori, Juha A. \& Guillaume, Xavier T. \& Andersen, Rune S. (tulossa 2020): Making peace visible: Colours in visual peace research - Peace \& Change 45:1.

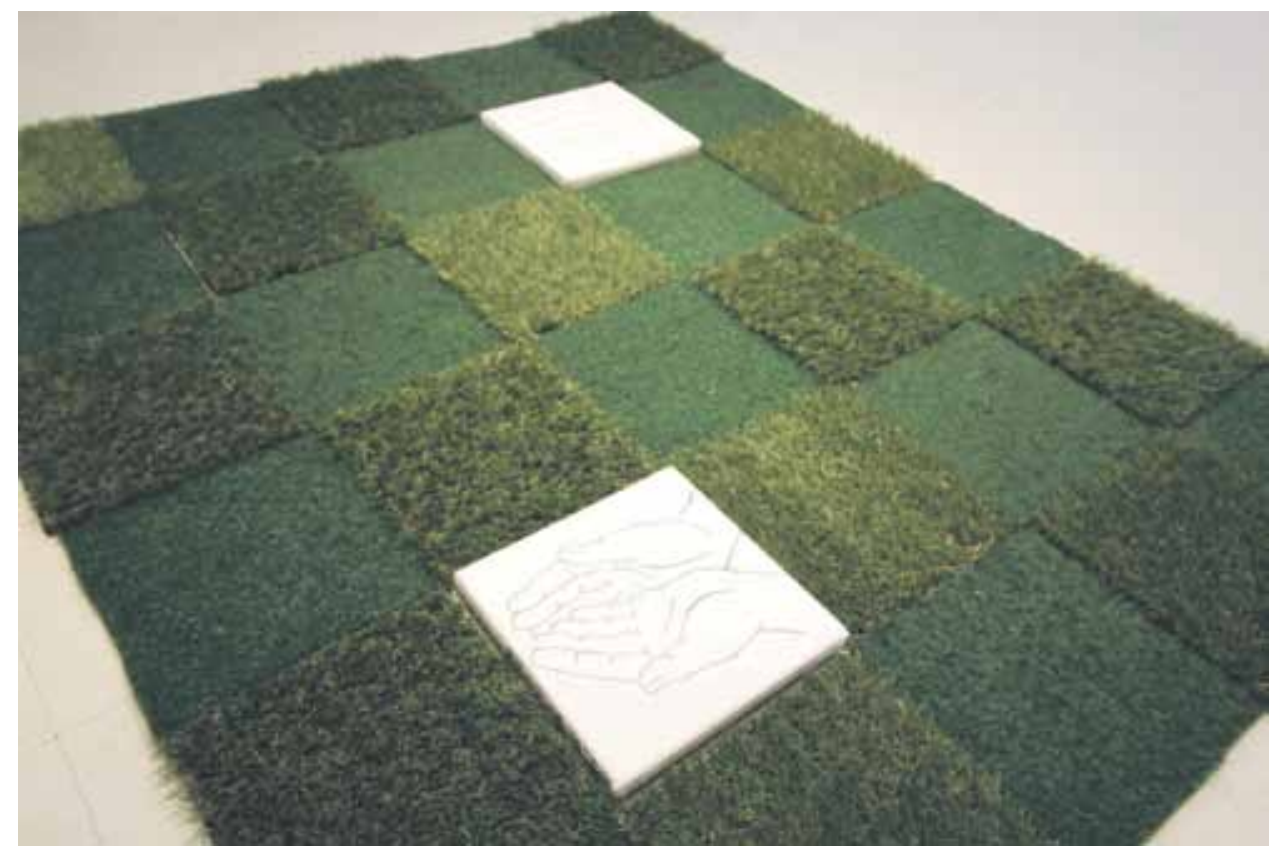

Piece of Grass.

\section{Margarita Rosselló Ramónin pitämiä hankkeen taidenäyttelyitä:}

Colourboratory Vol. 1, Galerie Pleiku Berliinissä 25.6.-15.7.2018

Colourboratory Vol. 2, Studio Mältinranta Tampereella 29.9.-16.10.2018

Colourboratory Vol. 3, Gallery TILA Helsingissä 4.-26.5.2019

Colourboratory Vol. 4, The HUG Space Madridissa syyskuu ja lokakuu 2019 


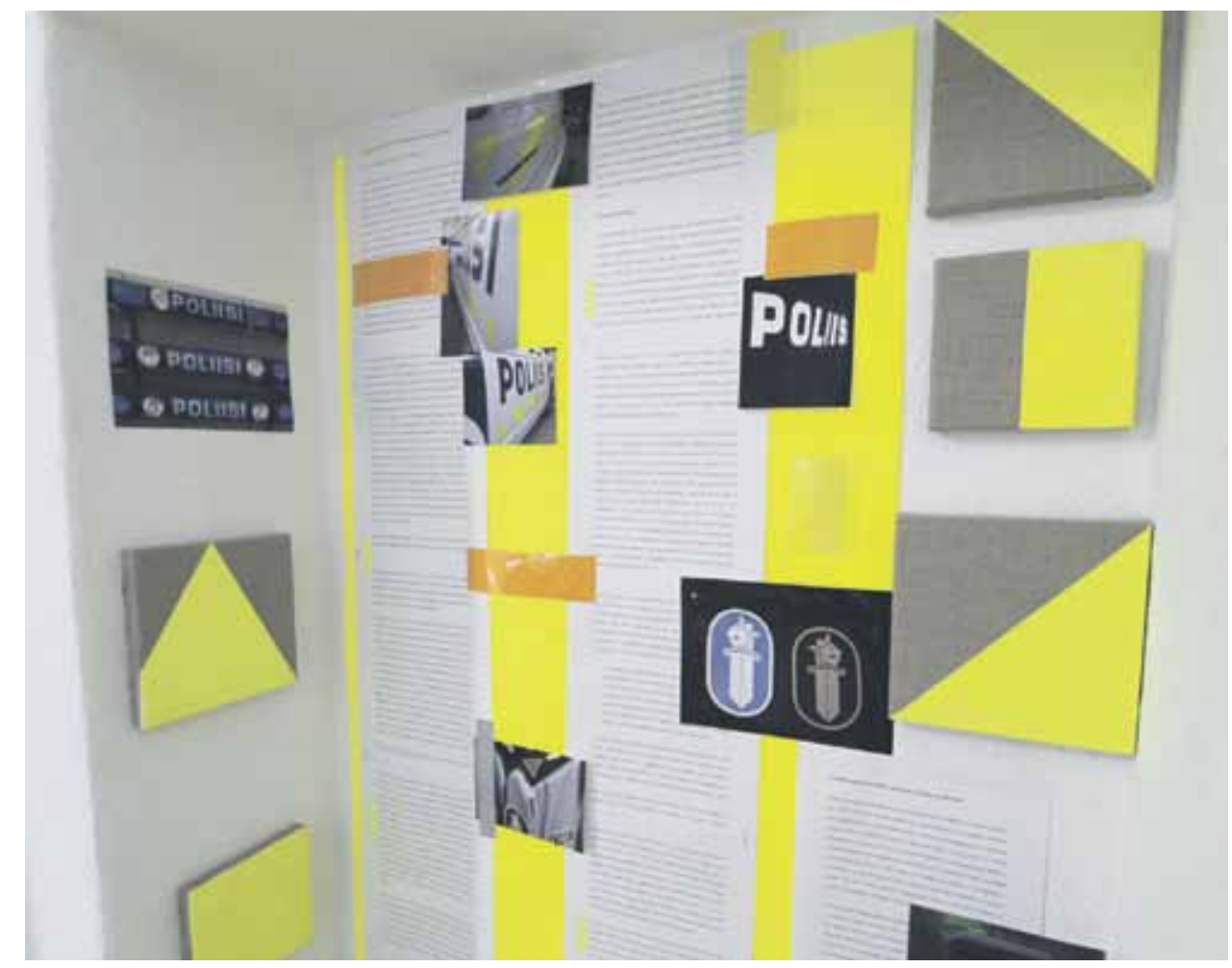

A Study in Yellow.

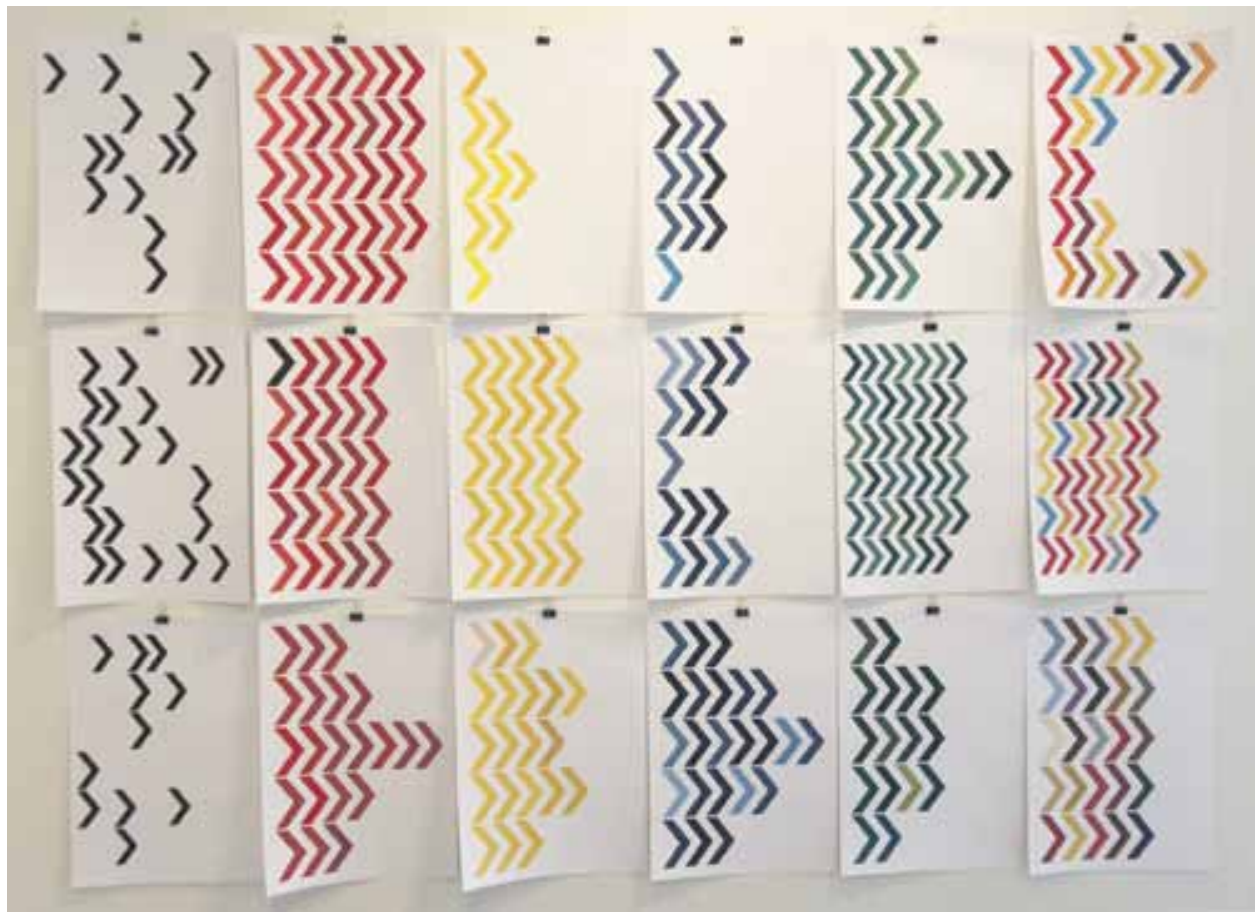

Code I II III.

96 IDÄNTUTKIMUS 3/2019 


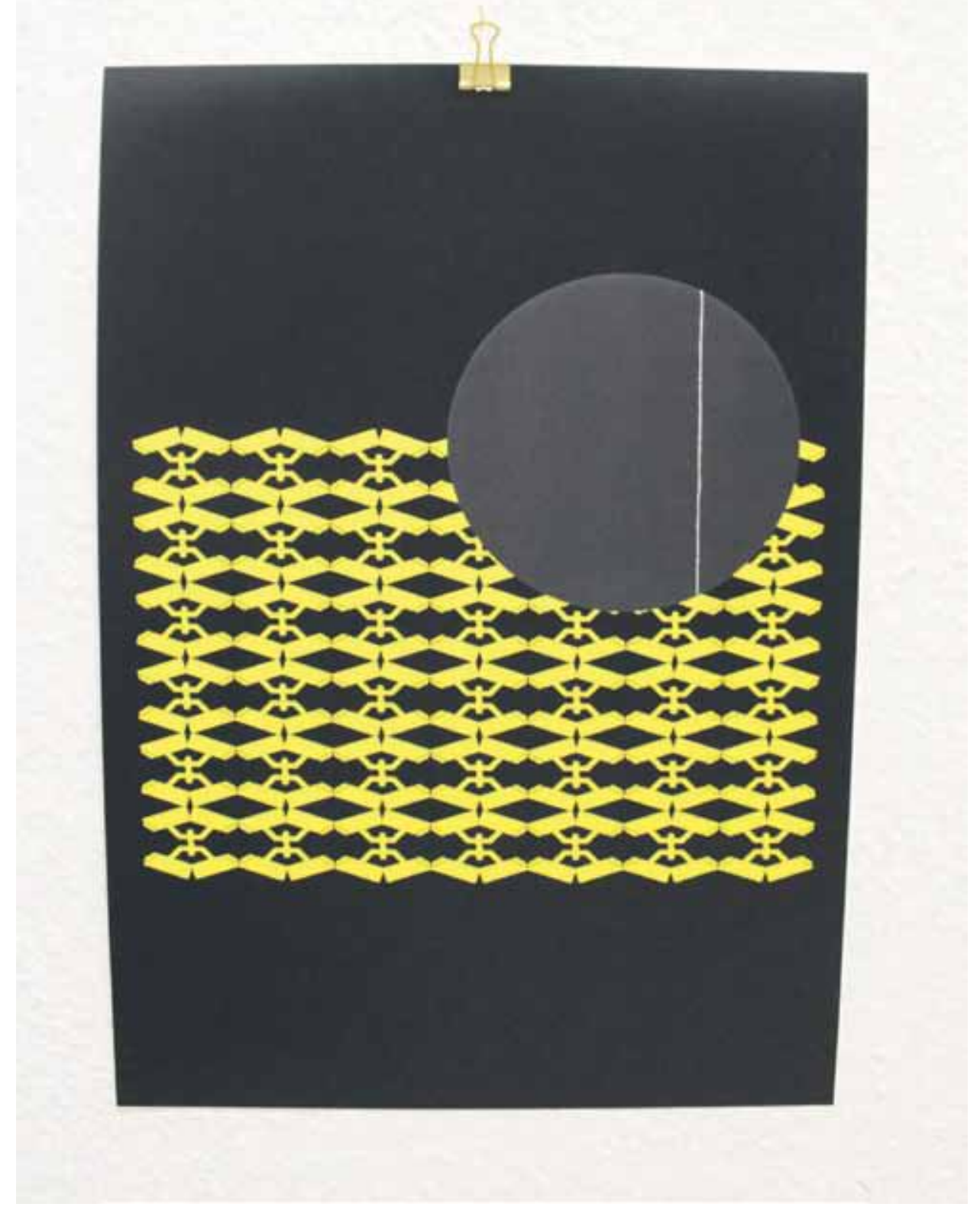

Greyscale (yksityiskohta). 